\title{
Preconceito: relações com a ideologia e com a personalidade
}

\author{
Prejudice: ideology and personality associations
}

José Leon CROCHÍK'1,2

\begin{abstract}
Resumo
O objetivo deste estudo é verificar se há relação entre a personalidade e a ideologia com o preconceito. A amostra é composta por 47 estudantes de Administração de Empresas e de 92 estudantes de Psicologia de uma universidade de São Paulo. Utilizaram-se a escala F, construída por Adorno, Frenkel-Brunswik, Levinson e Stanford em 1950, uma escala de posicionamento político e as escalas de ideologia da racionalidade tecnológica, de características narcisistas de personalidade e de manifestação de preconceitos - essas três últimas elaboradas pelo autor deste trabalho. Foram encontradas correlações significantes entre todas as variáveis, com destaque para as relações das escalas F e ideologia da racionalidade tecnológica com a escala de manifestação de preconceitos. Conclui-se que a ideologia e a personalidade são variáveis importantes na constituição do preconceito.
\end{abstract}

Palavras-chave: ideologia da racionalidade tecnológica; narcisismo; personalidade narcisista; preconceito.

\begin{abstract}
The aim of this research is to verify if there is a correlation among prejudice, personality and ideology. The sample was composed by 47 first-year Business Administration students, and 92 Psychology ones, all of them from one university of São Paulo. The F scale, a politic position measure and three other scales (prejudice manifestations, narcissistic traits of personality, and rational technology ideology) were used. Significant correlation was observed among all variables, especially between F scale, rational technology ideology and prejudice manifestations. In this way, ideology and personality are relevant variables in the prejudice determination.
\end{abstract}

Key words: rational technology ideology; narcissism; narcissistc personality; prejudice.

Na década de 1940, Adorno, Frenkel-Brunswik, Levinson e Sanford (1950) publicaram o seu estudo sobre a personalidade autoritária. Tinham como objetivo verificar a relação entre adesão a tipos de ideologia política-econômica - liberal ou conservadora - e configurações de personalidade - predispostas ou não ao fascismo - e, portanto, ao preconceito. A hipótese era de que necessidades psíquicas mediavam a escolha de ideologias, e assim aqueles que seriam predispostos a desenvolver preconceitos tenderiam a aderir à ideologia conservadora, e aqueles que não tivessem essa predisposição dariam preferência à ideologia liberal, que se configurava, à época, como a perspectiva de tornar a sociedade mais justa e os homens mais livres; e a ideologia conservadora, como a perspectiva de manter o status quo. Estudiosos da sociedade que foram, entendiam que quer as ideologias quer as personalidades são mediadas socialmente, ou seja, não

\section{$\boldsymbol{\nabla \nabla} \boldsymbol{\nabla} \boldsymbol{v}$}

1 Programas de Estudos Pós-Graduação em Psicologia Social e em Educação: História, Política, Sociedade, Pontifícia Universidade Católica de São Paulo. Rua Ministro Godoy, 969, Perdizes, 05015-901, São Paulo, SP, Brasil. E-mail: <jlchna@usp.br>.

2 Instituto de Psicologia, Universidade de São Paulo. Caixa Postal 66261, 05508-900, São Paulo, SP, Brasil.

Agradecimentos: ao CNPq pelo financiamento e aos auxiliares de pesquisa Ricardo Casco, Danilo Ide e Sávia Enrich. 
podem ser entendidas em si mesmas, mas somente à luz da configuração social. Dos resultados que interessam diretamente a esta pesquisa, podem-se destacar as correlações entre as escalas do antisemitismo e do etnocentrismo com a escala F, o que trouxe dados para assinalar dimensões que estariam subjacentes ao preconceito, tais como: agressividade autoritária, submissão ao autoritarismo, superstição, moralismo sexual, entre outras, e as correlações, de magnitude intermediária, entre a escala F, e as que avaliaram explicitamente o preconceito, com a escala de conservadorismo político-econômico. Esse último resultado permitiu confirmar, ao menos parcialmente, a hipótese do estudo acima explicitada.

Se a escala F avalia também traços sadomasoquistas de personalidade (Adorno, 1986a; Rouanet, 1989; Altemeyer, 1998), indica uma outra configuração de personalidade, que tem se desenvolvido em conformidade com necessidades sociais: a narcisista. Segundo ele, cada sociedade leva os indivíduos às regressões psíquicas que necessita para a sua reprodução. Em um estudo anterior, em conjunto com Horkheimer, indicou que no capitalismo concorrencial, do século XIX, o indivíduo poderia ser entendido como uma'pequena empresa psicológica', estruturado pelas três instâncias psíquicas - o ego, o id e o superego como Freud pôde descrevê-lo mais tarde, no capitalismo administrado, o que o caracteriza é a ausência de uma consciência moral bem estabelecida e o desenvolvimento de um ego frágil (Horkheimer \& Adorno, 1985). Assim, mudanças sociais acarretariam alterações nas configurações psíquicas existentes.

Estudos das últimas décadas têm se dedicado ao narcisismo; entre eles, ganharam notoriedade o de Lasch (1983) e, em nosso meio, o de Costa (1984). Trata-se de uma configuração psíquica ou traços de personalidade (Green, 1988) que se caracterizam pela retirada do interesse do indivíduo da realidade externa a ele, centrando-o em seu próprio eu. As relações que o narcisista estabelece tem como fito menos a adaptação social do que a satisfação de desejos relacionados predominantemente consigo mesmo, quase não se vinculando com necessidades coletivas. Claro, a autoconservação é importante, mas para o surgimento do indivíduo, tal como é definido pelo liberalismo do século XIX (Horkheimer \& Adorno, 1978), é importante também o estabelecimento de uma consciência individual que se articule com uma consciência social. O 'eu', segundo Adorno (1986a), é dialético, parte determinada por impulsos individuais, parte pela modificação desses devida à adaptação à sociedade. O'eu', para Freud (1974), deve mediar a relação entre os desejos do id e as possibilidades de sua realização. O narcisista, por sua vez, dá primazia a seus desejos, só considerando o 'princípio da realidade' em conformidade com eles. Em termos psíquicos, o narcisismo é mais regredido do que o sadomasoquismo. Adorno (1986a) diz que o narcisista sacrifica a consciência e Lasch (1983) indica que corresponde à fase oral do desenvolvimento psicossexual, tal como descrito pela psicanálise. Segundo Lasch (1983), a configuração psíquica do narcisista é adequada à atual configuração social, que pode prescindir, de acordo com Adorno (1986a), de um ego bem estruturado. Se Adorno baseia-se, principalmente, em Freud para suas considerações sobre o narcisismo, Lasch toma como uma de suas referências básicas a teoria de Melanie Klein; ainda que essa distinção seja importante para o entendimento desse conceito, ela não será discutida neste trabalho, considerando-se sua necessária delimitação. Cabe ressaltar, todavia, que em outro texto essa discussão foi efetuada (Crochík, 2004) e que para o presente artigo, considerou-se que as distintas análises de Adorno e de Lasch são complementares.

A sociedade capitalista, por sua vez, segundo Marcuse (1982) e Adorno (1986b), mesmo já tendo cumprido o seu objetivo de desenvolver consideravelmente as forças produtivas, continua a reproduzir as relações de poder existentes entre as classes sociais. E isso tem ocorrido em detrimento da possibilidade de uma sociedade justa, igualitária e que promova a liberdade, e com o auxílio de um tipo distinto de ideologia do existente no capitalismo concorrencial: a ideologia da racionalidade tecnológica. A ideologia liberal, segundo Horkheimer e Adorno (1978), era simultaneamente falsa e verdadeira: verdadeira porque os valores que defendia eram universais - liberdade, igualdade, justiça; falsa porque a sociedade capitalista se desenvolve privilegiando a classe daqueles que detêm os meios de produção. Já a ideologia contemporânea é basicamente justificativa para a preservação do sistema existente. Segundo Marcuse 
(1998), talvez a racionalidade tecnológica seja já ideologia, ou seja, a preparação de indivíduos competitivos, eficientes, produtivos, ao mirar unicamente a produção de bens, ocultando as relações de produção, auxilia na perpetuação da sociedade existente. É verdade que a ideologia liberal também procedia a essa ocultação, mas não abandonara aqueles valores citados acima, que na atual se vislumbram basicamente na necessidade de integração à sociedade (Adorno, 1972). Para os liberais, a sociedade precisava ser modificada, ainda que não em sua estrutura; para a atual ideologia, o que resta é a integração do indivíduo às instituições existentes.

Calcado nos trabalhos de Marcuse (1982) e de Horkheimer e Adorno (1985), Crochík (1999; 2000) estudou a atual ideologia da racionalidade tecnológica. Menos que a conteúdos, ela se refere a procedimentos operacionais de pensamento e ação que tomam como modelo a lógica da tecnologia e o pensamento formal. O mundo e, portanto, a adaptação a ele devem ser percebidos pela lógica formal. Assim, para essa ideologia, não haveria conflitos políticos, educacionais ou psicológicos, eles são reduzidos por ela a problemas de má-adaptação ao existente, que com o auxílio dos meios técnicos e da lógica poderiam ser resolvidos. A transformação da sociedade não estaria mais em questão. Na relação entre cultura e sociedade, a primeira quase que se teria reduzido à última. A cultura e a sua representante - a ideologia - fortaleceriam a integração social do indivíduo, mas diminuiriam a crítica às mesmas.

No estudo sobre a personalidade autoritária, Adorno descreve um tipo de personalidade autoritária - o manipulador - que, ainda que apresente uma configuração sadomasoquista, tem marcantes características narcisistas. O manipulador transforma os indivíduos, inclusive ele mesmo, em coisas, e obtém prazer utilizando-os para conseguir o que foi planejado. Ilustra, dessa forma, a relação entre características narcisistas e sadomasoquistas de personalidade e a ideologia da racionalidade tecnológica. Esse autor alega que na pesquisa sobre a personalidade autoritária existiam poucos sujeitos desse tipo, mas que tendo em vista a configuração social, ele tenderia a se tornar mais freqüente. Em um texto posterior (Adorno, 1995), esse autor volta a explicitar esse tipo de personalidade, corroborando a sua afirmação anterior.
Se, como dito antes, as mudanças sociais provocam a necessidade de novas configurações psíquicas e se essas são mediadas pela cultura a qual a ideologia representa, Crochík (1999; 2000) pressupôs em relação ao estudo de Adorno et al. (1950) que haveria relação entre a adesão à ideologia da racionalidade tecnológica, tal como descrita antes neste artigo, que estaria substituindo as ideologias políticas, e características narcisistas de personalidade. Elaborou uma escala para cada uma dessas variáveis - ideologia da racionalidade tecnológica e características narcisistas de personalidade - e, em conjunto com a escala F, aplicou-as a estudantes universitários. Obteve correlações significantes entre essas três variáveis e, de fato, aquele que tende a expressar a ideologia da racionalidade tecnológica tende também a apresentar traços de narcisismo e vice-versa, mas encontrou uma correlação ainda maior entre os escores da escala F e os da escala da ideologia, o que o levou à suposição de que as tendências implícitas fascistas seriam mais fortes para abrigar o pensamento tecnológico do que as características narcisistas. Como a escala F avalia também tendências sadomasoquistas, pensou-se que essas seriam adequadas a uma sociedade hierárquica como a atual, posto que na hierarquia deve-se obedecer quem se encontra numa posição mais elevada e submeter os que estão em posição subalterna; a obediência poderia estar associada ao prazer masoquista, e a dominação, ao prazer sádico.

Tendo em vista o estudo de Adorno et al. (1950), caberia saber se, mais de meio século depois, as relações por eles encontradas - da personalidade e da ideologia com o preconceito - se mantêm, considerando-se também um outro tipo de personalidade - a narcisista e um outro tipo de ideologia - a da racionalidade tecnológica. Assim, os objetivos desta pesquisa são: verificar se existem relações entre, de um lado, a adesão à ideologia da racionalidade tecnológica, as características narcisistas de personalidade, a predisposição ao fascismo e o conservadorismo político e, de outro lado, a manifestação de preconceitos.

\section{Método}

Participaram da pesquisa 139 estudantes que cursavam o primeiro ano dos cursos de Administração 
de Empresas - 47 sujeitos (turma de 2002) - e de Psicologia - 92 sujeitos (turma de 2001 - 43 sujeitos e turma de 2002 - 49 sujeitos) de uma universidade de São Paulo. A idade dos sujeitos variou de 18 a 23 anos. A amostra foi composta de 60 sujeitos do sexo masculino e 79 do sexo feminino.

Foram utilizados para este estudo um questionário de dados pessoais que, além de questões sobre idade e sexo, continha questões que procuravam saber a religião, a cor da pele e se os sujeitos tinham deficiência física e/ou contato próximo com pessoas portadoras de deficiência mental.

Foram utilizados também cinco escalas a saber:

1) Escala de Autocategorização Política (escala C): numerada de 0 a 10 pontos, consiste de uma linha de dez centímetros, com a palavra 'esquerda' no início da reta, correspondendo ao número 0 e a palavra 'direita' ao seu final, indicando o número 10. O sujeito deve indicar com um ' $X$ ', na reta, a sua posição no contínuo político. Entende-se que o termo 'direita', como já é consensual, refere-se ao conservadorismo político, assim, quanto maior o escore nessa escala, mais politicamente conservador seria o sujeito. Foi empregada anteriormente por Monteiro e Castro (1999).

2) Escala F: Elaborada por Adorno et al. (1950), visa avaliar a tendência de os indivíduos aderirem ao fascismo. É uma escala com itens tipo Likert, com seis alternativas de resposta, variando de discordância total (-3 pontos) à concordância total (+ 3 pontos). A pontuação é convertida para valores positivos que variam de 1 a 7 pontos. A escala F, segundo Adorno et al. (1965), na forma utilizada nesta pesquisa (forma 40/45), obteve índices de precisão de, em média, 0,90. Pesquisas das últimas décadas (Stankov, 1977; Rofé \&Weller, 1981) têm utilizado essa escala, ampliando a sua validade. Mais recentemente vem sendo substituída pela escala elaborada por Altemeyer (1998) - a escala Right-Wing Authoritarianism. Como nessa última escala, a teoria utilizada para a elaboração dos itens foi a da aprendizagem social, optou-se pela utilização da escala F, que contém, em sua elaboração, reflexões teóricas semelhantes às desta pesquisa. Dos 29 itens originais, só não foi utilizado o item 22 por ser específico à época em que a escala foi construída. Assim, a escala é composta de 28 itens. O Alpha de Cronbach, obtido para os sujeitos desta pesquisa, foi igual a 0,84.
Com a mesma estrutura de apresentação da escala F, ou seja, itens de tipo Likert e seis alternativas de resposta, três outras escalas foram construídas pelo autor desta pesquisa: escala da ideologia da racionalidade tecnológica (escala I); escala de características narcisistas de personalidade (escala N) e escala de manifestação de preconceitos (escala P). Quanto maior a pontuação nessas escalas, maior deve ser a adesão à ideologia da racionalidade tecnológica, maior o número de características narcisistas de personalidade e maior o grau de preconceito. As referências teóricas que originaram os itens das escalas I e N, os seus itens, seus resultados psicométricos em aplicações anteriores, assim como suas análises fatoriais, foram apresentados em Crochík (1999; 2000).

3) Escala da Ideologia da Racionalidade Tecnológica (escala I): Foi adaptada da formulada por Crochík (1999) para 20 itens (inicialmente tinha 46 itens), e, como tal, já foi utilizada em outro trabalho (Crochík, 2000). Para os sujeitos desta pesquisa apresentou um Alpha de Cronbach de 0,82.

4) Escala de Características Narcisistas de Personalidade (escala N): Foi também adaptada da construída por Crochík (1999) e por Severiano (2001) para 20 itens (inicialmente tinha 42 itens). Nesta pesquisa, o Alpha de Cronbach encontrado foi de 0,76.

5) Escala de Manifestação de Preconceitos (escala P): também foi construída em formato semelhante ao da escala F. Essa escala foi construída visando a quatro alvos distintos de preconceito, dois deles relacionados a questões ditas étnicas: o judeu e o negro, e outros dois, a deficiências: física e mental. As afirmações foram elaboradas a partir de outras escalas, tais como a Escala de Anti-semitismo e a Escala de Etnocentrismo, elaboradas por Adorno et al. (1950), e da literatura específica sobre o preconceito contra os quatro alvos analisados. Ela contém 48 afirmações, doze para cada alvo do preconceito examinado. Os seus itens são apresentados no Anexo 1. Essa escala foi aplicada sucessivamente a três amostras, semelhantes à utilizada neste estudo, antes de atingir a forma atual. Para os sujeitos desta amostra, o Alpha de Cronbach obtido foi igual a 0,90.

Quanto ao procedimento, as escalas foram apresentadas em conjunto para os sujeitos na seguinte ordem: questionário de dados pessoais, escala I, escala 
N, escala F, escala P e escala C. Importante ressaltar que os sujeitos pertencentes às minorias examinadas pela escala P foram identificados por meio do questionário de dados pessoais, e que os seus dados não foram computados para este estudo. Como forma de controle da veracidade das respostas dos sujeitos, utilizou-se, nesta pesquisa, uma mesma afirmação em duas escalas distintas e depois foi verificado se os sujeitos tinham respondido a ambas da mesma forma; quando isso não ocorreu, as respostas dos sujeitos em questão não foram consideradas; quando o foram, somente a pontuação de uma dessas duas afirmações foi computada.

Para cada sujeito, foram calculados os escores médios nas escalas I, N, P e F, que variaram de um a sete pontos e para escala C o escore foi o valor indicado na semi-reta apresentada. Foram utilizadas as seguintes provas estatísticas paramétricas: a análise de variância para comparar os escores dos sujeitos nas diversas escalas, quanto ao sexo e ao curso, e a correlação de Pearson para estabelecer a relação entre os escores dessas escalas.

\section{Resultados}

Inicialmente os sujeitos foram divididos em quatro grupos: AM - estudantes de Administração do sexo masculino $(n=35)$; AF - estudantes de Administração do sexo feminino ( $n=12)$; PsiM - estudantes de Psicologia do sexo masculino ( $n=25)$; e Psif - estudantes de Psicologia do sexo feminino ( $n=67$ ). São apresentadas as médias e os desvios-padrão dos escores obtidos nos diversos instrumentos para esses quatro grupos (Tabela 1).

Segundo os dados da Tabela 1, pode-se observar que os sujeitos da amostra como um todo apresen- taram, em média, um grau de conservadorismo político pouco abaixo do ponto médio dessa escala, que varia de zero a dez pontos; uma tendência de adesão à ideologia da racionalidade tecnológica e características narcisistas de personalidade próximas ao ponto médio dessas escalas; e as médias dos escores da escala F e da escala de manifestação de preconceitos mais de um ponto abaixo do ponto médio da escala. Os desvios-padrão, considerando a amplitude das escalas, não foram grandes.

A comparação desses grupos em todas as escalas, pela Análise de Variância, com 3 e 136 graus de liberdade, mostrou haver diferenças significantes entre eles ao nível de 0,01, em quase todas elas; a exceção foi a escala de características narcisistas de personalidade $(\mathrm{F}=2,19 ; p=0,09)$. Os resultados obtidos para as outras escalas foram: escala $C$ : $F=3,65$; escala $F: F=12,64$; escala I: $F=12,76$; e escala $P: F=4,06$.

Para saber entre quais grupos havia diferenças, nas escalas C, I, F e P, calculou-se outras análises de variâncias, comparando os estudantes de Administração de Empresas com os de Psicologia, independentemente do sexo; os estudantes do sexo masculino com os do sexo feminino do curso de Administração; e os estudantes do sexo masculino com os do sexo feminino do curso de Psicologia.

Quando comparados os escores dos sujeitos de Administração com os de Psicologia, apresentaram diferenças nas seguintes escalas: I ( $F=30,39 ; 1$ e 138 graus de liberdade e $p<0,05), P(F=11,14 ; 1$ e 138 graus de liberdade e $p<0,01$ ) e $F(F=34,76 ; 1$ e 138 graus de liberdade e $p<0,05)$. Não apresentaram diferenças na escala $C$ ( $F=4,72 ; 1$ e 138 graus de liberdade, $p<0,01)$.

Os estudantes do sexo masculino do curso de Administração não se diferenciaram, nas diversas escalas,

Tabela 1. Médias e desvios-padrão dos escores das escalas para as amostras.

\begin{tabular}{|c|c|c|c|c|c|c|c|c|c|c|c|}
\hline \multirow{2}{*}{ Escalas } & \multicolumn{2}{|r|}{ AM } & \multicolumn{2}{|r|}{$\mathrm{AF}$} & \multicolumn{2}{|c|}{ PsiM } & \multicolumn{2}{|c|}{ PsiF } & \multicolumn{3}{|c|}{ Total } \\
\hline & $M$ & $\pm \mathrm{DP}$ & $M$ & $\pm \mathrm{DP}$ & M & $\pm \mathrm{DP}$ & $M$ & $\pm \mathrm{DP}$ & M & \pm & $\mathrm{DP}$ \\
\hline$C$ & 4,6 & $\pm 1,9$ & 4,8 & $\pm 2,2$ & 3,2 & $\pm 1,5$ & 4,2 & $\pm 1,7$ & 4,2 & \pm & 1,8 \\
\hline F & 3,5 & $\pm 0,7$ & 3,2 & $\pm \quad 0,8$ & 2,5 & $\pm \quad 0,7$ & 2,7 & $\pm 0,6$ & 2,9 & \pm & 0,8 \\
\hline I & 4,2 & $\pm 0,9$ & 4,2 & $\pm \quad 0,8$ & 3,0 & $\pm \quad 0,8$ & 3,5 & $\pm 0,9$ & 3,6 & \pm & 1,0 \\
\hline $\mathrm{N}$ & 3,8 & $\pm 0,9$ & 4,1 & $\pm \quad 0,9$ & 3,4 & $\pm \quad 0,9$ & 3,6 & $\pm 0,7$ & 3,7 & \pm & 0,8 \\
\hline P & 2,7 & $\pm 0,7$ & 2,9 & $\pm \quad 0,9$ & 2,3 & $\pm \quad 0,6$ & 2,4 & $\pm 0,6$ & 2,5 & \pm & 0,7 \\
\hline
\end{tabular}

$\mathrm{AM}=$ estudantes de administração do sexo masculino; $\mathrm{AF}=$ estudantes de administração do sexo feminino; PsiM= estudantes de Psicologia do sexo masculino; PsiF= estudantes de Psicologia do sexo feminino. 
dos estudantes do sexo feminino. Com 1 e 46 graus de liberdade e $p<0,01$, foram obtidos os seguintes resultados: escala I: $F=0,03$; escala $P$ : $F=0,80$; escala $C$ : $F=0,09$; e escala $F: F=1,16$.

Já os estudantes de sexo masculino do curso de Psicologia diferenciaram-se dos sujeitos de sexo feminino na escala I ( $F=6,20$; 1 e 92 graus de liberdade e $p<0,01)$ e na escala $C(F=6,78 ; 1$ e 92 graus de liberdade e $p<0,05)$ e não apresentaram diferenças significantes na escala $P(F=0,17 ; 1$ e 92 graus de liberdade e $p<0,05)$ e na escala $F$ ( $F=0,20 ; 1$ e 92 graus de liberdade).

Em virtude desses resultados, as análises de correlações efetuadas entre os escores obtidos nas diversas escalas foram feitas: para a amostra como um todo; para os estudantes do curso de Administração, sem distinção dos sexos; para os estudantes do sexo masculino do curso de Psicologia; e para os estudantes do sexo feminino do curso de Psicologia.

Quanto às correlações de Pearson entre os escores obtidos nas diversas escalas para a amostra total de estudantes (Tabela 2), pode-se observar, em primeiro lugar, que todas as variáveis se correlacionaram positivamente ao nível de 0,001. Além disso, destaca-se a magnitude das correlações entre a escala F, de um lado, e as escalas I e P, de outro, ou seja, quanto maior o escore na escala F, maior a adesão à ideologia da racionalidade tecnológica e maior o grau de preconceito. Como a principal variável de nosso estudo foi o preconceito, deve-se destacar também que quanto maior o escore na escala P, maior o número de traços narcisistas de personalidade, maior o conservadorismo político e maior a adesão à ideologia da racionalidade tecnológica e vice-versa.

Para a mostra de estudantes de Administração, todas as correlações foram significantes, mas em níveis

Tabela 2. Correlações de Pearson entre as escalas para a amostra total de estudantes.

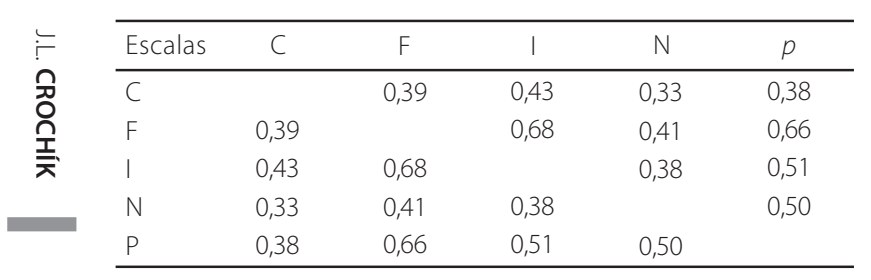

314

$p<0,001$. de significância distintos (Tabela 3). A escala F novamente apresentou maiores magnitudes de correlação com as outras variáveis. A escala C foi menos correlacionada com as outras variáveis nos estudantes de Administração, quando comparada com a amostra total, ainda que, segundo a Tabela 1, os escores médios nessa escala tenham sido maiores do que para os estudantes de Psicologia. Todas as outras variáveis estão significantemente relacionadas à manifestação de preconceito, ao nível de 0,001.

Tabela 3. Correlações de Pearson entre as escalas na amostra de estudantes de Administração.

\begin{tabular}{lccccc}
\hline Escalas & $\mathrm{C}$ & $\mathrm{F}$ & \multicolumn{1}{c}{$\mathrm{I}$} & $\mathrm{N}$ & \multicolumn{1}{c}{$p$} \\
\hline $\mathrm{C}$ & & $0,32^{*}$ & $0,34^{*}$ & $0,43^{* * *}$ & $0,40^{*}$ \\
$\mathrm{~F}$ & $0,32^{*}$ & & $0,62^{* * *}$ & $0,47^{* * *}$ & $0,68^{* * *}$ \\
$\mathrm{I}$ & $0,34^{*}$ & $0,62^{* * *}$ & & $0,45^{* * *}$ & $0,46^{* * *}$ \\
$\mathrm{~N}$ & $0,43^{* * *}$ & $0,47^{* * *}$ & $0,45^{* * *}$ & & $0,49^{*}$ \\
$\mathrm{P}$ & $0,40^{* *}$ & $0,68^{* * *}$ & $0,46^{* * *}$ & $0,49^{* * *}$ & \\
\hline
\end{tabular}

${ }^{*} p<0,05 ;{ }^{* *} p<0,01 ;{ }^{* * *} p<0,001$.

Na Tabela 4, são apresentadas as correlações entre as diversas variáveis na amostra de estudantes de Psicologia do sexo masculino. Chama a atenção a ausência de correlações significantes, aos níveis estabelecidos, entre a escala $C$ e as escalas de características narcisistas de personalidade e a de manifestação de preconceito. Nessa amostra, as escalas F, I e N correlacionaram-se com a escala P respectivamente com os seguintes níveis: 0,001,0,01 e 0,05.

Tabela 4. Correlações de Pearson entre as escalas na amostra de estudantes de Psicologia do sexo masculino.

\begin{tabular}{lccccl}
\hline Escalas & \multicolumn{1}{c}{$\mathrm{C}$} & $\mathrm{F}$ & \multicolumn{1}{c}{$\mathrm{I}$} & $\mathrm{N}$ & \multicolumn{1}{c}{$p$} \\
\hline $\mathrm{C}$ & & $0,53^{* *}$ & $0,64^{* * *}$ & 0,28 & 0,35 \\
$\mathrm{~F}$ & $0,53^{* *}$ & & $0,63^{* * *}$ & $0,50^{* *}$ & $0,70^{* * *}$ \\
$\mathrm{I}$ & $0,64^{* * *}$ & $0,69^{* * *}$ & & $0,53^{* *}$ & $0,49^{* *}$ \\
$\mathrm{~N}$ & 0,28 & $0,50^{* *}$ & $0,53^{* *}$ & & $0,47^{*}$ \\
$\mathrm{P}$ & 0,35 & $0,70^{* * *}$ & $0,49^{* *}$ & $0,47^{*}$ & \\
\hline
\end{tabular}

${ }^{*} p<0,05 ;{ }^{* *} p<0,01 ;{ }^{* * *} p<0,001$

Já a correlações de Pearson entre as variáveis encontradas na amostra de estudantes de Psicologia do sexo feminino, ao contrário do ocorrido com as 
outras amostras, nessa, a escala $\mathrm{N}$ só se correlacionou com a escala de manifestação de preconceitos (Tabela 5). As demais escalas apresentaram correlações significantes a 0,001 com a escala P, com exceção da escala $C$, que obteve uma correlação significante com essa escala a 0,01.

Tabela 5. Correlações de Pearson entre as escalas na amostra de estudantes de Psicologia do sexo feminino.

\begin{tabular}{lccccc}
\hline Escalas & \multicolumn{1}{c}{$\mathrm{C}$} & $\mathrm{F}$ & \multicolumn{1}{c}{ I } & $\mathrm{N}$ & \multicolumn{1}{c}{$P$} \\
\hline $\mathrm{C}$ & & $0,30^{* *}$ & $0,32^{* *}$ & 0,18 & $0,30^{*}$ \\
$\mathrm{~F}$ & $0,30^{* *}$ & & $0,56^{* * *}$ & 0,23 & $0,54^{* * *}$ \\
$\mathrm{I}$ & $0,32^{* *}$ & $0,56^{* * *}$ & & 0,18 & $0,45^{* *}$ \\
$\mathrm{~N}$ & 0,18 & 0,23 & 0,18 & & $0,49^{*}$ \\
$\mathrm{P}$ & $0,30^{* *}$ & $0,54^{* * *}$ & $0,45^{* * *}$ & $0,49^{* * *}$ & \\
\hline
\end{tabular}

${ }^{*} p<0,05 ;{ }^{* *} p<0,01 ;{ }^{* * *} p<0,001$.

\section{Discussão}

O escore médio dos sujeitos desta pesquisa obtido na escala de manifestação de preconceitos foi baixo (média de 2,5) tendo em vista o seu ponto médio (4 pontos). Os sujeitos universitários da pesquisa de Adorno et al. (1950) apresentaram um escore médio mais elevado em sua escala sobre o etnocentrismo (entre 3 e 4 pontos). Se as distinções de época, lugar e configuração das escalas em questão não podem ser menosprezadas, não se pode também deixar de considerar que os resultados obtidos nesta pesquisa talvez se devam a uma diminuição do preconceito flagrante, análogo ao racismo flagrante que, segundo trabalhos recentes (Vala, Brito \& Lopez, 1999), tem sido substituído pelo racismo sutil, ou racismo simbólico. Ou seja, pode ser que os baixos escores obtidos na escala P possam ser entendidos pela modificação do tipo de preconceito existente numa cultura claramente contrária a ele, de forma que se deveria utilizar medidas indiretas para avaliá-lo. Ou talvez esse resultado indique que, efetivamente, os sujeitos da presente pesquisa sejam menos preconceituosos do que os do estudo de Adorno et al. (1950).

Para se pensar as duas possibilidades aventadas acima, cabe mencionar que a escala $F$ foi elaborada com o intuito de ser uma medida indireta do preconceito, e que, no presente estudo, o escore médio obtido nessa escala foi também inferior ao encontrado por Adorno et al. (1950) em seus sujeitos universitários. Além disso, no estudo de Berkeley, para esses sujeitos, as correlações obtidas entre os escores na escala F e os da escala de etnocentrismo variaram de 0,58 a 0,79, enquanto no presente estudo a correlação entre a escala F e a escala P foi, considerando todos os sujeitos, igual a 0,66 , ou seja, a correlação entre a escala $\mathrm{F}$ e a manifestação de preconceitos foi de magnitude próxima nas duas pesquisas. Assim, considerando-se essas duas comparações, pode-se inferir que os sujeitos desta pesquisa tendem a ser menos preconceituosos do que os estudantes universitários que participaram do estudo de Berkeley.

O escore médio no contínuo político de dez pontos fornecido aos sujeitos desta pesquisa (4,2 pontos) indica uma posição de centro um pouco dirigida à vertente da esquerda, que foi um resultado similar ao obtido no estudo de Adorno et al. (1950). Mas a correlação obtida neste estudo entre o conservadorismo político e a escala $F$ foi menor do que as obtidas nas amostras de universitários daquele estudo. Enquanto se obteve, neste estudo, uma correlação de 0,39 entre essas duas variáveis, as obtidas em Berkeley variaram entre 0,29 e 0,54 (apenas uma das oito amostras universitárias do estudo de Adorno et al. obteve valor abaixo de 0,40). O mesmo pode ser dito da correlação entre a escala C e a escala de manifestação de preconceitos obtida neste estudo $(r=0,38)$ quando comparada com as correlações obtidas entre a escala de conservadorismo político-econômico e a escala de etnocentrismo para os sujeitos universitários de Adorno et al. (1950), que variaram entre 0,48 e 0,62. Para explicar esses dados, de início, deve ser ressaltado que a escala utilizada nesta pesquisa é distinta da construída por Adorno et al. (1950) para esse fim, mas ainda assim podese levantar a suposição de que a posição política, nos dias de hoje, tem menos peso na manifestação direta ou indireta de preconceitos. Isso talvez ocorra porque a distinção entre as alternativas políticas tenha diminuído, o que suscitaria ao menos duas possibilidades não incompatíveis entre si: a esfera da política estaria se tornando, cada vez mais, de menor interesse para os cidadãos, e estaria se transformando em uma questão essencialmente técnico-administrativa. A primeira possibilidade é ilustrada por Adorno (1995), que alega 
que os homens se sentem cada vez mais afastados das condições que governam a sua vida; a segunda indicaria o que Marcuse (1982) configura como a ideologia da sociedade industrial e que nesta pesquisa foi avaliada pela escala da ideologia da racionalidade tecnológica.

O escore médio obtido na escala de ideologia da racionalidade tecnológica foi próximo ao ponto médio da escala e as correlações quer com a escala $F$ $(r=0,68)$ quer com a escala $P(r=0,51)$ foram efetivamente superiores às obtidas entre essas variáveis e a escala C, O que fortalece a hipótese de que essa ideologia vem substituindo o papel que outrora as ideologias políticas ocupavam em relação ao preconceito. De outro lado, esses dados revelam que a mentalidade tecnológica tem relação importante quer com a existência de preconceitos quer com tendências implícitas de adesão ao fascismo. Isso seria coerente com a análise que Marcuse (1982) fez da ideologia da sociedade industrial. Essa ideologia seria apropriada para o tipo manipulador, descrito na introdução deste artigo. Segundo Adorno et al. (1950), ainda que seja um tipo de personalidade fixado na fase anal, tal como descrita pela psicanálise, apresenta também traços narcisistas.

Neste estudo, avaliou-se também a relação entre traços narcisistas de personalidade e a existência de preconceitos. A correlação obtida entre os escores da escala $\mathrm{N}$ e os da escala $\mathrm{P}(\mathrm{r}=0,50)$ foi menor do que a obtida entre os escores da escala F e os da escala $P$ $(r=0,66)$. Isso indica que os traços narcisistas estão menos relacionados ao preconceito do que o sadomasoquismo, que a escala F também avalia.

Assim, os dados desta pesquisa continuam a indicar, de forma similar ao estudo de Adorno et al. (1950), que o preconceito está associado à ideologia eà personalidade. De um lado, pode-se dizer que a ideologia política está menos relacionada ao preconceito do que a racionalidade tecnológica, de outro, que os traços sadomasoquistas de personalidade estão mais associados ao preconceito do que os narcisistas.

Por fim, resta comparar os resultados obtidos nas três amostras. Nessas, verifica-se a mesma tendência da amostra considerada como um todo, explicitada no parágrafo anterior, no que se refere às correlações das escalas C, I, F e N com a manifestação do preconceito (P). Essas três amostras, contudo, deixam de ser similares no que se refere à magnitude da expressão de algumas das variáveis examinadas. Assim, os estudantes de Administração de Empresas apresentaram escores significantemente maiores do que os seus colegas de Psicologia nas escalas I, F e P. Talvez as habilidades e motivações necessárias para a formação em Administração sejam mais associadas às capacidades de sistematização, hiper-realismo, normalização, que são valorizadas pela ideologia da racionalidade tecnológica, do que aquelas necessárias para a formação em Psicologia. Se isso é procedente, e se há relação entre a escala I e as escalas F e P, conforme mostram os dados desta pesquisa, esse resultado não é inesperado. De outro lado, não é fácil explicar porque as alunas de Psicologia tiveram escores significantemente maiores do que seus colegas de sexo masculino nas escalas I e C. Informações mais específicas sobre esse dado, obtidas em futuras pesquisas, podem dar subsídios importantes para isso.

Certamente, são necessários novos trabalhos com amostras similares às utilizadas neste estudo, que forneçam mais dados para confirmar ou não o que foi encontrado, assim como seria importante aplicar essas escalas para amostras de sujeitos não universitários, para verificar se as variáveis continuam a se relacionar da mesma forma. Cabe, no entanto, reafirmar com os dados desta pesquisa a importância da personalidade e da ideologia para o entendimento e combate ao preconceito, sem desconsiderar que ambas são mediadas socialmente, ou seja, são produtos da sociedade existente; assim, a nossa sociedade deveria ser alterada em sua estrutura, tornando-se justa e direcionada para as diferenças individuais, que comportam necessidades distintas, deixando de fomentar o desenvolvimento de preconceitos; enquanto isso não for possível, caberiam ações educacionais em diversos âmbitos - família, escola, trabalho -, que permitissem refletir quer sobre o preconceito, quer sobre suas relações com a ideologia e com as necessidades psíquicas propícias ao seu desenvolvimento, para que ele possa ser atenuado.

\section{Referências}

Adorno, T.W., Frenkel-Brunswik, E., Levinson, D.J., \& Sanford, R.N. (1950). The authoritarian personality. New York: Harper and Row. 
Adorno, T.W. (1972). Teoría de la seudocultura. In T.W. Adorno. Filosofía y superstición (pp.141-174). Madrid: Alianza Editorial.

Adorno, T.W. (1986a). Acerca de la relación entre Sociologia y Psicologia. In H. Jensen (Org.). Teoria crítica del sujeto (pp.36-83). Buenos Aires: Siglo XXI.

Adorno, T.W. (1986b). Capitalismo tardio ou sociedade industrial? In T.W. Adorno. Sociologia (pp.62-75). São Paulo: Ática.

Adorno, T.W. (1995). Educação após Auschwitz. In T.W. Adorno. Palavras e sinais (pp.104-123). Petrópolis: Vozes.

Altmeyer, B. (1998). The other authoritarian personality. Advances In Experimental, 47-91.

Costa, J.F. (1984). Violência e psicanálise. Rio de Janeiro: Graal.

Crochík, J.L. (1999). A personalidade narcisista e a ideologia da racionalidade tecnológica. Tese de livre docência não-publicada, Instituto de Psicologia, Universidade de São Paulo.

Crochík, J.L. (2000). Tecnologia e individualismo: um estudo de uma das relações contemporâneas entre ideologia e personalidade. Análise Psicológica (Portugal), 4 (18), 529-543.

Crochík, J.L. (2004). Apontamentos sobre o narcisismo da perspectiva da Teoria Crítica da Sociedade. Jornal de Psicanálise, 37 (68),193-222.

Freud, S. (1974). O Ego e o id. Pequena coleção das obras de Freud. Rio de Janeiro: Imago.

Green, A. (1988). Narcisismo de vida, narcisismo de morte. São Paulo: Escuta.
Horkheimer, M., \& Adorno, T.W. (1978). Temas básicos de sociologia. São Paulo: Editora Cultrix.

Horkheimer, M., \& Adorno, T.W. (1985). W. Dialética do esclarecimento (2. ed.) Rio de Janeiro: Jorge Zahar.

Lasch, C. (1983). A Cultura do narcisismo. Rio de Janeiro: Imago.

Marcuse, H. (1982). Aldeologia da sociedade industrial (6a. ed.) Rio de Janeiro: Zahar.

Marcuse, H. (1998). Industrialização e capitalismo na obra de Max Weber. In H. Marcuse. Cultura e sociedade (v. 2). São Paulo: Paz e Terra.

Monteiro, M.B., \& Castro, P. (1999). Cada cabeça sua sentença. Oeira: Celta Editora.

Rouanet, S.P. (1989). Teoria crítica e psicanálise. Rio de Janeiro: Tempo Brasileiro.

Rofé, Y., \& Weller, L. (1981). Attitudes toward the enemy as a function of level of threat. British Journal of Social Psychology, 20 (3), 217-218.

Severiano, M.F.V. (2001). Narcisismo e publicidade. São Paulo: Annablume.

Stankov, L. (1977). Some experiences with the F scale in Yugoslavia. The British Journal of Social and Clinical Psychology, 16 (2), 111-121.

Vala, J., Brito, R., \& Lopez, D. (1999). Expressões dos racismos em Portugal. Lisboa: ISCTE.

Recebido para publicação em 4 de fevereiro de 2004 e aceito em 17 de maio de 2005 


\section{Anexo 1 \\ Itens da Escala de Manifestação de Preconceitos}

1) Os judeus, com exceções, parecem preferir um modo de vida mais luxuoso, extravagante e sensual.

2) As pessoas portadoras de deficiência física, por si só, têm dificuldades de obter empregos, por isso seria importante que organizações sociais as auxiliassem nisso.

3) O avanço da medicina em seus métodos de detectar imperfeições nos fetos é importante pois dificulta o nascimento de seres com deficiência mental.

4) Dificilmente uma pessoa portadora de deficiência mental poderá trazer alguma contribuição efetiva à sociedade.

5) O portador de deficiência física, na maioria das vezes, me incomoda, pois lembra a imperfeição humana.

6) Como negros e brancos têm preferências específicas quanto a tipos de música e de dança, não é de se estranhar que existam casas noturnas freqüentadas quase exclusivamente por negros e outras por brancos.

7) Geralmente as pessoas portadoras de deficiência mental não são atraentes.

8) Os judeus parecem se adaptar melhor a trabalhos que não exigem o esforço corporal.

9) Avanço da medicina em seus métodos de detectar imperfeições nos fetos é importante pois impede o nascimento de seres com defeitos físicos.

10) Não me é indiferente ter amigos brancos ou negros.

11) Em geral, por mais que se esforce, um portador de deficiência física não consegue fazer as atividades do cotidiano tão bem como as pessoas normais.

12) Em geral, os portadores de deficiência física tentam compensar sua deficiência sobressaindo-se nas atividades intelectuais.

13) Os negros têm uma tendência natural para o esporte e para a música, por isso exercem melhor esses tipos de atividades do que atividades intelectuais e administrativas.

14) O pior que pode acontecer com uma pessoa é ser portadora de deficiência mental.

15) Num bairro maioritariamente composto por não judeus, estes deveriam se empenhar para que os judeus evitassem constituir grupos isolados, para o melhor convívio de toda a comunidade.

16) A escravidão do negro foi intensa, no passado, devido, em parte, à aceitação do trabalho escravo pelo negro.

17) Por mais que tente, uma pessoa portadora de defeitos físicos tem dificuldades de ser feliz, pois a deficiência a impede de atingir a plenitude da vida.

18) Teria receio de colocar meus filhos em escolas que aceitam crianças portadoras de deficiência mental, pois estas são imprevisíveis.

19) Os brancos conseguem, em geral, obter melhores empregos do que os negros, pois são mais disciplinados quanto às regras estabelecidas pelas empresas.

20) Para a própria felicidade das pessoas portadoras de deficiência física, é importante que haja escolas especiais, trabalhos específicos e formas de lazer que permitam agrupá-las.

21) Em uma comunidade de 1000 brancos e 50 negros, um negro bêbado mata acidentalmente um policial também negro, que tentava prendê-lo. Essa comunidade deveria considerar a possibilidade de não permitir que os negros bebam em demasia.

22) Teria dúvidas de matricular meus filhos em uma escola judaica.

23) É melhor que os judeus freqüentem as suas próprias organizações - clubes, escolas etc -, já que têm interesses e costumes específicos.

24) Os deficientes mentais devem ter escolas especiais para educá-los, pois em escolas regulares atrapalham o aprendizado dos que não são deficientes.

25) As pessoas portadoras de deficiência física tendem a se considerar vítimas.

26) A valorização que o judeu dá ao dinheiro dificulta o seu relacionamento com outras pessoas.

27) Os deficientes mentais, em geral, não conseguem se fazer entender.

28) Os negros, geralmente, são menos preocupados com o trabalho do que as outras pessoas.

29) Para preservar melhor a cultura negra, talvez fosse interessante repensar os casamentos mistos.

30) A maior parte do sistema financeiro do país é dominada por judeus, de modo que esses exercem demasiada influência na política econômica nacional.

31) Prefiro não ter filhos, a ter um filho portador de deficiência física.

32) Os negros talvez devessem seguir os mesmos hábitos de limpeza dos brancos para adquirir menos doenças.

33) É provável que os milionários judeus prestem alguma ajuda à sua própria gente, mas muito pouco de seu dinheiro se destina a outras causas nobres. 
34) A ausência de controle nas ocupações em cargos de liderança faz com que os judeus, em geral, levem vantagem sobre os não-judeus.

35) Por mais adaptado que pareça um judeu, sempre lhe resta algo essencialmente judeu, uma lealdade ao judaísmo e uma maneira de ser que nunca muda por completo.

36) É algo incômodo ter amigos portadores de deficiências físicas.

37) Em uma sociedade democrática, os negros deveriam se comportar como a maioria dos brancos.

38) Em algumas profissões, que exigem o curso universitário, há grande número de judeus. Seria desejável um sistema social mais igualitário, no qual todos os povos estivessem igualmente representados.

39) Não é possível, em geral, uma pessoa que nasça com deficiência física não ter ressentimentos em relação a seus pais.

40) Os negros, freqüentemente, estão mais preocupados com o presente do que com o futuro.

41) As pessoas portadoras de deficiência mental não deveriam se casar com pessoas normais, pois a chance de gerar filhos deficientes é alta.

42) Os deficientes mentais, em geral, não podem competir em atividades físicas em igualdade de condições com as pessoas normais.

43) A presença de um portador de deficiência mental, na maior parte das vezes, causa-me mal-estar.

44) As escolas judaicas deveriam dar menos ênfase ao judaísmo e mais atenção a valores como o de solidariedade.

45) Seria importante que as pessoas portadoras de deficiência mental recebessem uma educação especializada que as possibilitasse trabalhar em atividades que não exijam grande esforço intelectual.

46) As pessoas portadoras de deficiência física não deveriam casar entre si, pois poderiam ter dificuldades de cuidar de seus filhos.

47) O negro parece-me, freqüentemente, dotado de uma potência sexual maior do que a do branco.

48) Seria melhor para todos que as pessoas portadoras de deficiência mental tivessem espaços próprios de convivência, onde ficariam mais à vontade para se expressar e trocar experiências. 
